\title{
Ankle brachial index measurement in primary care: are we doing it right?
}

Saskia PA Nicolä̈, Lotte M Kruidenier, Ellen V Rouwet, Marie-Louise EL Bartelink, Martin H Prins and Joep AW Teijink

\section{ABSTRACT}

Background

The reference standard for diagnosing peripheral arterial disease in primary care is the ankle brachia index (ABI). Various methods to measure ankle and brachial blood pressures and to calculate the index are described.

Aim

To compare the $\mathrm{ABI}$ measurements performed in primary care with those performed in the vascular laboratory. Furthermore, an inventory was made of methods used to determine the $A B I$ in primary care.

Design of study

Cross-sectional study.

Setting

Primary care practice and outpatient clinic

\section{Method}

Consecutive patients suspected of peripheral arterial disease based on $\mathrm{ABI}$ assessment in primary care practices were included. The $A B I$ measurements were repeated in the vascular laboratory. Referring GPs were interviewed about method of measurement and calculation of the index. From each patient the leg with the lower $\mathrm{ABI}$ was used for analysis.

\section{Results}

Ninety-nine patients of 45 primary care practices with a mean $\mathrm{ABI}$ of 0.80 (standard deviation $[\mathrm{SD}]=0.27$ ) were included. The mean $\mathrm{ABI}$ as measured in the vascular laboratory was $0.82(S D=0.26)$. A Bland-Altman plot demonstrated great variability between $A B I$ measurements in primary care practice and the vascular laboratory. Both method of blood pressure measurements and method of calculating the $A B I$ differed greatly between primary care practices.

\section{Conclusion}

This study demonstrates that the ABI is often not correctly determined in primary care practice. This phenomenon seems to be due to inaccurate methods for both blood pressure measurements and calculation of the index. A guideline for determining the $\mathrm{ABI}$ with a hand-held Doppler, and a training programme seem necessary.

Keywords

diagnosis; Doppler effect; intermittent claudication; peripheral vascular diseases; ultrasonography.

\section{INTRODUCTION}

GPs play a key role in the diagnosis and treatment of patients with peripheral arterial disease. As international guidelines recommend, the reference standard for diagnosing peripheral arterial disease in primary care is measurement of the ankle brachial index (ABI). An $A B I<0.9$ indicates the presence of peripheral arterial disease in symptomatic patients as well as in asymptomatic patients. In addition, an $\mathrm{ABI}<0.9$ reflects the presence of generalised asymptomatic atherosclerotic disease, and its associated increased cardiovascular risk. ${ }^{1}$ There is an increased use of the $A B I$ in primary care as an effect of the upcoming office-based cardiovascular screening and prevention programmes, since current guidelines recommend to initiate secondary prevention of atherosclerotic disease in all patients with an $\mathrm{ABI}<0.9 .^{2}$ Moreover, reimbursement, one of the limitations of incorporating $A B I$ into daily practice ${ }^{3}$ was recently introduced in the Netherlands for $\mathrm{ABI}$ measurement in primary care.

The $A B I$ is a non-invasive, simple, and inexpensive

SPA Nicolaï, MD, PhD student; LM Kruidenier, MD, PhD student, Department of Surgery Atrium Medical Center Parkstad, Heerlen, The Netherlands. EV Rouwet, MD, PhD, fellow in vascular surgery, Department of Surgery, Erasmus Medical Centre, Rotterdam, The Netherlands. MEL Bartelink, $M D$, PhD, Julius Center for Health Sciences and Primary Care, University Medical Center Utrecht, The Netherlands. MH Prins, MD, PhD, professor of epidemiology, Department of Epidemiology, Maastricht University, The Netherlands. JAW Teijink, MD, PhD, vascular surgeon, Department of Surgery, Catharina Hospital, Eindoven, The Netherlands.

Address for correspondence

JAW Teijink, Department of Surgery, Catharina Hospital, PO Box 1350, 5602 ZA, Eindhoven, The Netherlands. E-mail: joep.teijink@catharina-ziekenhuis.nl

Submitted: 10 September 2008; Editor's response: 6 November 2008; final acceptance: 9 December 2008.

@British Journal of General Practice.

This article was originally online first on 15 May 2009. Cite this article as: Br J Gen Pract 2009; 59: 422-427. Advance online publication. DOI: 10.3399/bjgp09X420932 
test with a good diagnostic performance if determined by well-trained professionals. ${ }^{4,5}$ However, reproducibility of the $A B I$ is dependent on training and experience of the observer, which may be difficult in primary care practice. Moreover, there are various ways to perform the measurement and to calculate the index. ${ }^{6-9}$ Arm pressures can be measured at one or two arms, and ankle pressures at the posterior tibial and/or the dorsal pedal artery. In the situation that systolic pressures of two arms or two ankle arteries are measured, the highest, average, or lowest pressure can be used for calculating the index. Theoretically, this results in at least 25 different possible combinations to calculate the $\mathrm{ABI}$.

This study aimed to compare the reported results of $\mathrm{ABI}$ measurements performed in primary care with those performed in the vascular laboratory, with attention to the method used for blood pressure measurement and calculation of the index. In addition, an inventory was made of the techniques used and ways to measure and calculate the ABI.

\section{METHOD}

All consecutive patients suspected of symptomatic peripheral arterial disease, based on their complaints accompanied with an $\mathrm{ABI}$ measurement in primary care practice, who were referred to the researchers' outpatient vascular clinic by their GP were included in this study. All GP practices performing $A B I$ Doppler measurements from the region of the Atrium Medical Center Parkstad, the Netherlands, were eligible for inclusion.

Informed consent was obtained from all patients; all referring GPs were informed about the ongoing study and informed consent was also obtained.

Methods of $\mathrm{ABI}$ measurement in the primary care practices were determined by a questionnaire about the resting period prior to blood pressure measurements, method of ankle and brachial systolic blood pressure measurements, numerator and denominator for calculation of the $A B I$, frequency of $\mathrm{ABI}$ assessment, and specialised training. Questionnaires were administered after inclusion of the patients.

In all patients the $A B I$ measurement was repeated in the vascular laboratory within a short period of time, varying between 1 and 4 weeks. Following a 15minute resting period, systolic blood pressures in the brachial, dorsal pedal, and posterior tibial arteries were determined in a supine position, with a handheld pocket Doppler device (Doppler MD2, $8 \mathrm{MHz}$, Huntleigh Healthcare, Cardiff, UK), by a trained vascular technician blinded for the primary care $A B I$. Brachial and ankle pressures were measured with $10 \mathrm{~cm}$-wide sphygmomanometer cuffs, which were manually inflated and deflated. The first audible signal

\section{How this fits in}

The reference standard for diagnosing peripheral arterial disease in primary care is measurement of the ankle brachial index (ABI). This study demonstrates that there is great variability between $A B I$ measurements within primary care practice as well as the vascular laboratory. Both method of blood pressure measurements and method of calculating the $A B I$ differed greatly between primary care practices. A guideline for determining the $A B I$ with a hand-held Doppler, and a training programme seem necessary.

of the first ventricular systole was used to identify the systolic blood pressure at each location. Brachial pressures were measured bilaterally and were repeated if the difference was $>10 \mathrm{mmHg}$ between the two arms. Ankle pressures were determined with cuffs placed proximal to the malleoli. For each leg, the $\mathrm{ABI}$ was calculated by dividing the highest systolic ankle pressure (either posterior tibial or dorsal pedal) by the highest systolic pressure of both arms. ${ }^{7}$ The lower $\mathrm{ABI}$ of both legs of each patient was used for further analysis.

\section{Analysis}

A Bland-Altman plot is used to compare two clinical measurement techniques that each provide some error, that is, where there is no gold standard that provides the exact information. ${ }^{10}$ The Bland-Altman plot is therefore used to visualise agreement between two measurement techniques. Because the true value is not known, on the horizontal axis the mean of both measurements is presented. On the vertical axis the difference between the two measurements is presented. A Bland-Altman plot explores a possible relationship between the measurement error and the true value, for example in this study a lack of agreement between the two methods with the lower or the higher ABls can be visualised with this plot. To assess if there was a dependency of the difference between the two measurements on the average of the measurements, univariate linear regression analysis was used. Another way to demonstrate variability between the two $A B I$ measurements is by means of the coefficient of variation. To this end, the average of and the difference between the two $A B I$ measurements were calculated for each patient. The coefficient of variation for the study population was calculated as the standard deviation of the differences between the two $A B I$ measurements divided by the mean of the averages. Then, the coefficient of variation was quoted as percentage. A coefficient of variation of $<10 \%$ to $15 \%$ is generally regarded as acceptable for clinical tests. Univariate linear regression analysis was performed to assess the dependency of who 
Figure 1. Average ankle brachial index $(A B I)$ as determined by the two measurements across the difference between the $A B I$ measurement in primary care practice and the measurement in the vascular laboratory $(S D=$ standard deviation).

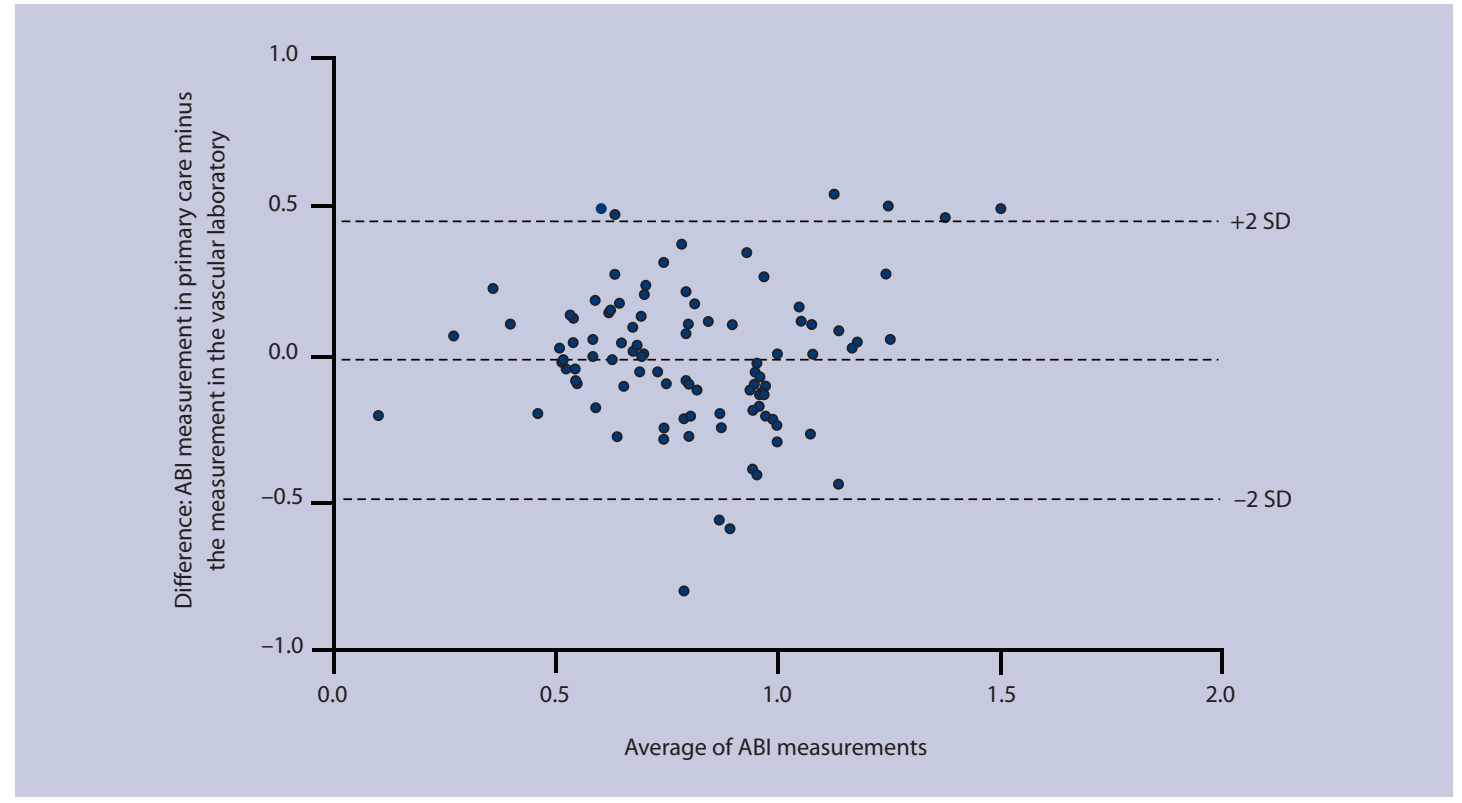

performed the measurements in primary care and the frequency of $\mathrm{ABI}$ measurements in primary care on the accuracy of the readings. In addition, a crosstabulation was made using an $\mathrm{ABI}<0.9$ and an $\mathrm{ABI} \geq 0.9$ as measured in primary care and in the vascular laboratory. The $\kappa$ and its $95 \%$ confidence interval $(\mathrm{Cl})$ were calculated. Statistical analysis was performed with SPSS (version 15.0 for Windows).

\section{RESULTS}

The vascular surgical department of the Atrium Medical Center Parkstad is a referral centre for approximately 140 GPs. Ninety-nine patients were referred by 61 different GPs from 46 primary care practices. Each GP referred a mean of 1.6 patients (standard deviation $[S D]=0.98$ ). The mean $A B I$ measured in the primary care setting was $0.80(\mathrm{SD}=$ $0.27,95 \% \mathrm{Cl}=0.75$ to 0.86 ) and in the vascular laboratory $0.82(\mathrm{SD}=0.26,95 \% \mathrm{Cl}=0.76$ to 0.87 ). The mean difference between the two measurements was $0.02(\mathrm{SD}=0.24,95 \% \mathrm{Cl}=-0.06$ to $0.03 ; P=$ 0.528). Agreement between the $A B I$ measurement in primary care and the $\mathrm{ABI}$ measurement performed in the vascular laboratory was visualised in a Bland-Altman plot (Figure 1). This plot depicts the difference between the measurement in primary care

Table 1. Cross-tabulation of the ABI measurements in primary care and in the vascular laboratory.

\begin{tabular}{lcc} 
& \multicolumn{2}{c}{ Vascular laboratory } \\
\hline & $\mathrm{ABI}<0.9$ & $\mathrm{ABI} \geq 0.9$ \\
\hline Primary care & & \\
$\mathrm{ABI}<0.9$ & 47 & 19 \\
$\mathrm{ABI} \geq 0.9$ & 9 & 24 \\
\hline
\end{tabular}

and the measurement in the vascular laboratory for each leg in relation to the average $\mathrm{ABI}$ as determined by the two measurements. Furthermore, the 'limits of agreement', which are expressed as $\pm 2 \mathrm{SD}$ are given in the figure. In this study these intervals are wide (SD 0.24 ), reflecting the great variation of the differences. ${ }^{10}$ Linear regression failed to show a relation for the difference of the measurements to the average of the measurements, indicating that the accuracy of the measurements is equal for all the $A B I$ measurements (high and low). The coefficient of variation between both measurements was $29.6 \%$, meaning that there is considerable variation between the measurement in primary care and that in the vascular laboratory.

The Bland-Altman plot implies that neither measurement counts as a 'gold standard'. However, to demonstrate the clinical relevance of the discrepancy in $\mathrm{ABI}$ measurements between primary practice and the vascular laboratory, the data were also presented in a cross-tabulation, classifying the results of the $A B I$ measurement as normal $(\geq 0.9)$ or abnormal $(<0.9)$ (Table 1). The agreement between primary care and the vascular laboratory was $0.41(\kappa$, $95 \% \mathrm{Cl}=0.22$ to 0.59 ), indicating a poor agreement beyond change. In 19 out of 66 patients referred with an $\mathrm{ABI}$ measurement $<0.9$ in primary care practice, the $A B I$ measurement was $\geq 0.9$ in the vascular laboratory. Assuming the vascular laboratory reading to be the gold standard, in these patients the diagnosis of peripheral arterial disease was rejected.

\section{Methods of $A B I$ determination in primary care practices}

The method of $A B I$ measurement was evaluated by telephone questionnaire. Forty-five out of 46 practices participated. ABI was determined by GPs in 
eight practices, and by a non-doctor in 37 practices. In 26 practices, the professional had followed a structured training for $A B I$ assessment. Linear regression did not show a difference in accuracy of $\mathrm{ABI}$ measurement between GPs and non-doctors ( $P$ $=0.213$ ). Furthermore, linear regression analysis did not reveal a difference between primary care practices performing an $\mathrm{ABI}$ measurement more or less than once a week $(P=0.524)$. The questionnaire showed that 34 out of 45 primary care practices planned a period of rest before the measurement was started. (Table 2). This period of rest varied between 5 and 20 minutes (mean 8.9 minutes, SD 4.2 minutes). In 41 primary care practices, bilateral systolic blood pressure of the arms was performed, and in the majority (28 practices) this was performed with a pocket Doppler device and a sphygmomanometer cuff. In the other cases, the systolic blood pressure was measured with a stethoscope and a sphygmomanometer (16 practices) or an oscillometric automatic device (one practice). In 23 practices, the systolic blood pressures of the dorsal pedal and the posterior tibial artery were determined in all patients, independent of their complaints. In the remaining 22 practices, the systolic blood pressure of one pedal artery was investigated - this was the tibial posterior or dorsal pedal artery in 15 and six practices, respectively. Eight different methods were used for calculation of the $\mathrm{ABI}$ in primary care practices. In primary care practices measuring the systolic blood pressure in two pedal arteries, the majority divided the highest ankle pressure by the highest arm pressure. However, other calculations used the mean of both ankle pressures and divided the right ankle pressure by the right arm pressure, and the left ankle pressure by the left arm pressure. Eight out of 45 primary care practices measured and calculated the $\mathrm{ABI}$ according to the method used in the vascular laboratory.

\section{DISCUSSION}

\section{Summary of main findings}

This study shows that, overall, $A B I$ measurements are comparable between primary care practices and the vascular laboratory. However, for the individual patient the $A B I$ as assessed in the GP's office may vary significantly from that assessed in the vascular laboratory. This may be related to the method of ankle and brachial blood pressure measurements as well as the calculation of the index.

\section{Strengths and limitations of the study}

In this study, blood pressure measurements were performed using a hand-held pocket Doppler device. The pocket Doppler is a relatively cheap and easy to use device with a good inter- and intra-observer

\begin{tabular}{lc}
$\begin{array}{l}\text { Table 2. Methods used in primary care practice to measure } \\
\text { ankle and brachial blood pressures. }\end{array}$ \\
$\begin{array}{lc}\text { Primary care practices, } \\
(n=45), n(\%)\end{array}$ \\
Part of ABI method & \\
\hline Resting period & $21(47)$ \\
$\geq 10$ minutes & $13(29)$ \\
$<10$ minutes & $10(22)$ \\
No rest & \\
\hline Brachial systolic pressure & $41(91)$ \\
Both arms & $4(9)$ \\
One arm & \\
\hline Device for blood pressure measurement & $28(62)$ \\
Doppler device & $16(36)$ \\
Korotkoff method & $1(2)$ \\
Automatic device & \\
\hline Ankle systolic pressure & $23(51)$ \\
Dorsal pedal and posterior tibial artery & $15(33)$ \\
Posterior tibial artery & $6(13)$ \\
Dorsal pedal artery & $1(2)$ \\
One unknown artery &
\end{tabular}

variability for $\mathrm{ABI}$ assessment, at least in trained operators. ${ }^{4,11,12}$ It has been shown that the reproducibility of $A B I$ assessment by pocket Doppler may be dependent on the level of experience of the operator. ${ }^{4,5}$ The most important limitations to incorporating $\mathrm{ABI}$ measurements in primary care are time constraints, while an $A B I$ measurement takes 12-15 minutes, ${ }^{3,13}$ reimbursement, and staff availability. ${ }^{3}$

Furthermore, in patients with peripheral arterial disease, there is variability in $\mathrm{ABI}$ measurements that is attributable to biological factors and can differ between days. Baker et al showed that the ABI must change by at least 0.15 before this can be considered significant. ${ }^{14}$ In this study, the second measurement was performed 1-4 weeks later than the measurement in primary care, which could at least partially explain the variability found between the measurements in primary care and in the vascular laboratory.

All patients included in this study were referred to the vascular laboratory for evaluation of suspected symptomatic peripheral arterial disease. Since the national guideline suggests that GPs can initiate treatment of patients with intermittent claudication by exercise therapy and cardiovascular risk management, ${ }^{15}$ it is not possible to say how many patients from these primary care practices were not referred to the vascular laboratory for an additional $\mathrm{ABI}$ measurement. Although it would be informative to investigate the number of missed diagnoses, the aim of the current study was to investigate the difference in $\mathrm{ABI}$ measurement as determined in primary care practice and in the vascular laboratory, not to assess patient outcome based on $A B I$ measurement in primary care practice.

It is possible that the results of this study cannot 
be directly translated to the 'healthy' screening population in general practice. However, this should not influence the method used to determine and calculate the $\mathrm{ABI}$ in primary care.

\section{Comparison with existing literature}

In this study, great variability is demonstrated between the $A B I$ measurement in primary care and in the vascular laboratory. Another recent study shows that $\mathrm{ABI}$ measurements by GPs and nurses are highly reproducible. ${ }^{16}$ However, reproducibility of the $A B I$ is dependent on the experience of the observer, $4,5,17$ and in the aforementioned study a limited number of selected GPs received specialised training before starting the study. This seems not to reflect the current situation in primary care.

National and international guidelines recommend the use of the $A B I$ in routine screening for atherosclerosis. ${ }^{2,7}$ Substantial prevalence rates of asymptomatic peripheral arterial disease in the older population in primary care, with at least one vascular risk factor, were found. ${ }^{18-20} \mathrm{~A}$ recent meta-analysis showed that a low $\mathrm{ABI}$ in a healthy screening population was associated with approximately twice the 10-year total mortality, cardiovascular mortality, and major coronary events. ${ }^{1}$ Current guidelines recommend initiation of secondary prevention of atherosclerotic disease in all patients with an $A B I$ $<0.9$. $^{2}$ Given the importance of the $A B I$ in the initial diagnosis of peripheral arterial disease, and as a predictor of cardiovascular morbidity and mortality in general, accurate determination of the $A B I$ is crucial for determining the cardiovascular risk profile and successful cardiovascular risk factor management.

Surprisingly, however, these guidelines do not provide step-by-step information about the correct method of $\mathrm{ABI}$ assessment. ${ }^{2,7,15}$ Moreover, different modes of determination and calculation of the $A B I$ are used and advised. ${ }^{6,8}$ Klein and Hage found 39 different ways to calculate the $\mathrm{ABI} .{ }^{8} \mathrm{~A}$ recently published literature analysis that evaluated the methodology of $\mathrm{ABI}$ determination in 100 random publications demonstrated great variability with respect to the methods of ankle and brachial blood pressure measurements as well as calculation of the index. ${ }^{8}$ This large variety in calculation of the $A B I$ can result in different reports of peripheral arterial disease prevalence..$^{21,22}$

Recently in the literature, attention has been paid to alternative methods to detect or exclude patients with peripheral arterial disease. However, the Edinburgh Claudication Questionnaire has an inadequate diagnostic value for detecting patients with peripheral arterial disease. ${ }^{23}$ Furthermore, pulse palpation has been shown by some authors to not be sensitive to detection of peripheral arterial disease; ${ }^{24,25}$ however, another study has suggested it is possible to exclude peripheral arterial disease by pulse palpation. ${ }^{26}$ Easier methods to measure the $\mathrm{ABI}$ are also described in the literature; however, results concerning the reliability of automated oscillometry to facilitate ABI measurement in clinical practice are contradictory. ${ }^{25,27-29}$

\section{Implications for further research and clinical practice}

This study demonstrates that the $A B I$ is often not correctly determined in primary care practice. This phenomenon seems to be due to inaccurate methods for both ankle and brachial blood pressure measurements and calculation of the index. A clear step-by-step guideline for determining the $A B I$ with a hand-held Doppler, and a training programme seem necessary.

\section{Ethical approval}

The study was approved by the medical ethical committee of the Atrium Medical Center Parkstad

\section{Competing interests}

The authors have stated that there are none

\section{Acknowledgements}

We would like to thank the vascular technicians who performed the ankle brachial index measurements in the vascular laboratory.

\section{Discuss this article}

Contribute and read comments about this article on the Discussion Forum: http://www.rcgp.org.uk/bjgp-discuss

\section{REFERENCES}

1. Fowkes FG, Murray GD, Butcher I, et al. Ankle brachial index combined with Framingham Risk Score to predict cardiovascular events and mortality: a meta-analysis. JAMA 2008; 300(2): 197-208.

2. Hirsch AT, Haskal ZJ, Hertzer NR, et al. ACC/AHA 2005 practice guidelines for the management of patients with peripheral arterial diseases (lower extremity, renal, mesenteric and abdominal aortic): a collaborative report from the American Association for Vascular Surgery/Society for Vascular Surgery, Society for Cardiovascular Angiography and Interventions, Society for Interventional Radiology, Society for Vascular Medicine and Biology, and the American College of Cardiology/American Heart Association Task Force on Practice Guidelines (Writing Committee to develop guidelines for the management of patients with peripheral arterial disease). Circulation 2005; 113(11): e463-e654.

3. Mohler ER III, Treat-Jacobson D, Reilly MP, et al. Utility and barriers to performance of the ankle-brachial index in primary care practice. Vasc Med 2004; 9(4): 253-260.

4. Kaiser V, Kester AD, Stoffers HE, et al. The influence of experience on the reproducibility of the ankle-brachial systolic pressure ratio in peripheral arterial occlusive disease. Eur J Vasc Endovasc Surg 1999; 18(1): 25-29.

5. Matzke S, Franckena M, Alback A, et al. Ankle brachial index measurements in critical leg ischaemia - the influence of experience on reproducibility. Scand J Surg 2003; 92(2): 144-147.

6. Greenland P, Abrams J, Aurigemma GP, et al. Prevention Conference $\mathrm{V}$ : beyond secondary prevention: identifying the high-risk patient for primary prevention: noninvasive tests of atherosclerotic burden: Writing Group III. Circulation 2000; 101(1): E16-22.

7. Norgren L, Hiatt WR, Dormandy JA, et al. Inter-society consensus for the management of peripheral arterial disease (TASC II). J Vasc Surg 2007; 45(suppl): S5-67.

8. Klein S, Hage JJ. Measurement, calculation, and normal range of the ankle-arm index: a bibliometric analysis and recommendation for standardization. Ann Vasc Surg 2006; 20: 282-292.

9. Caruana MF, Bradbury AW, Adam DJ. The validity, reliability, reproducibility and extended utility of ankle to brachial pressure index in current vascular surgical practice. Eur J Vasc Endovasc Surg 2005; 29(5): 443-451.

10. Bland JM, Altman DG. Statistical methods for assessing agreement 
between two methods of clinical measurement. Lancet 1986; 1(8476): 307-310.

11. Aboyans V, Lacroix P, Lebourdon A, et al. The intra- an interobserver variability of ankle-arm blood pressure index according to its mode of calculation. J Clin Epidemiol 2003; 56(3): 215-220.

12. Stoffers HE, Kester AD, Kaiser V, et al. The diagnostic value of the measurement of the ankle-brachial systolic pressure index in primary health care. J Clin Epidemiol 1996; 49(12): 1401-1405.

13. Bendermacher BL, Teijink JA, Willigendael EM, et al. Applicability of the ankle brachial index measurement as screening device in general practice for high cardiovascular risk. In: Bendermacher BLW. Peripheral arterial disease, screening, diagnosis, and conservative treatment. Rotterdam: Thieme Media Center, 2007: 6-59.

14. Baker JD, Dix DE. Variability of Doppler ankle pressures with arterial occlusive disease: an evaluation of ankle index and brachial-ankle pressure gradient. Surgery 1981; 89(1): 134-137.

15. Bartelink M, Stoffers HE, Boutens EJ, et al. NHG-standaard perifeer arterieel vaatlijden. [Peripheral arterial disease; guideline for general practice]. Huisarts Wet 2003; 46: 848-858.

16. Holland-Letz T, Endres HG, Biedermann S, et al. Reproducibility and reliability of the ankle-brachial index as assessed by vascular experts, family physicians and nurses. Vasc Med 2007; 12(2): 105-112.

17. Ray SA, Srodon PD, Taylor RS, Dormandy JA. Reliability of ankle:brachial pressure index measurement by junior doctors. $\mathrm{Br} J$ Surg 1994; 81(2): 188-190.

18. Hirsch AT, Criqui MH, Treat-Jacobson D, et al. Peripheral arterial disease detection, awareness, and treatment in primary care. JAMA 2001; 286(11): 1317-1324.

19. Diehm C, Lange S, Darius H, et al. Association of low ankle brachial index with high mortality in primary care. Eur Heart J 2006; 27(14): 1743-1749.

20. Bendermacher BL, Teijink JA, Willigendael EM, et al. A clinical prediction model for the presence of peripheral arterial disease the benefit of screening individuals before initiation of measurement of the ankle-brachial index: an observational study. Vasc Med 2007; 12(1): 5-11.

21. McDermott MM, Criqui MH, Liu K, et al. Lower ankle/brachial index, as calculated by averaging the dorsalis pedis and posterior tibial arterial pressures, and association with leg functioning in peripheral arterial disease. J Vasc Surg 2000; 32(6): 1164-1171.

22. Lange SF, Trampisch HJ, Pittrow D, et al. Profound influence of different methods for determination of the ankle brachial index on the prevalence estimate of peripheral arterial disease. BMC Public Health 2007; 7: 147.

23. Bendermacher BL, Teijink JA, Willigendael EM, et al. Symptomatic peripheral arterial disease: the value of a validated questionnaire and a clinical decision rule. Br J Gen Pract 2006; 56(533): 932-937.

24. Collins TC, Suarez-Almazor M, Peterson NJ. An absent pulse is not sensitive for the early detection of peripheral arterial disease. Fam Med 2006; 38(1): 38-42.

25. Aboyans V, Lacroix P, Doucet $S$, et al. Diagnosis of peripheral arterial disease in general practice: can the ankle-brachial index be measured either by pulse palpation or an automatic blood pressure device? Int J Clin Pract 2008; 62(7): 1001-1007.

26. Migliacci R, Nasorri R, Ricciarini P, Gresele P. Ankle-brachial index measured by palpation for the diagnosis of peripheral arterial disease. Fam Pract 2008; 25(4): 228-232.

27. Beckman JA, Higgins CO, Gerhard-Herman M. Automated oscillometric determination of the ankle-brachial index provides accuracy necessary for office practice. Hypertension 2006; 47(1): 35-38.

28. Gardner AW, Montgomery PS. Comparison of three blood pressure methods used for determining ankle/brachial index in patients with intermittent claudication. Angiology 1998; 49(9): 723-728.

29. MacDougall AM, Tandon V, Wilson MP, Wilson TW. Oscillometric measurement of ankle-brachial index. Can J Cardiol 2008; 24(1): 49-51. 